\title{
LA DIVERSIDAD FUNCIONAL EN COLOMBIA: PROTECCIÓN DE LAS PERSONAS CON DISCAPACIDAD EN EL SISTEMA DE SEGURIDAD SOCIAL COLOMBIANO
}

THE FUNCTIONAL DIVERSITY IN COLOMBIA: THE PROTECTION OF PERSONS WITH DISABILITIES IN THE COLOMBIAN SOCIAL SECURITY SYSTEM

\section{JOSÉ LUIS RUIZ SANTAMARÍA}

Profesor de Derecho del Trabajo y de la Seguridad Social

Universidad de Málaga 


\title{
RESUMEN
}

En los últimos tiempos, la protección de las personas con discapacidad en Colombia ha experimentado un notable progreso, pasando del "modelo médico rehabilitador" al "modelo social" que pone el énfasis en la rehabilitación de una sociedad, que ha de ser concebida y diseñada para hacer frente a las necesidades de todas las personas, gestionando las diferencias e integrando la diversidad. En un principio, su sistema de Seguridad Social Integral, reglamentado primordialmente por la Ley 100 de 1993, contenía una única protección de las personas frente a la invalidez; sin embargo, en años posteriores se ha producido un amplio desarrollo jurisprudencial y normativo que ha contribuido a extender esta protección a un mayor número de personas.

PALABRAS CLAVE: Protección, Personas con Discapacidad, Colombia, Seguridad Social, Convención de Naciones Unidas sobre los Derechos de las Personas con Discapacidad, Convenio Multilateral Iberoamericano de Seguridad Social.

\begin{abstract}
In recent years, the protection of persons with disabilities has made remarkable progress in Colombia, moving from the "rehabilitative medical model" to the "social model" which emphasis on the rehabilitation of a society, which must be conceived and designed to address everybody's needs, managing differences and integrating diversity. Initially, its Integral Social Security system, ruled primarily by Law 100 of 1993, contained a single protection of people against disability; however, in later years there has been an extensive jurisprudential and normative development, which has contributed to grant this protection to more people.
\end{abstract}

KEYWORDS: Protection, Persons with Disabilities, Colombia, Social Security, UN Convention on the Rights of Persons with Disabilities, Ibero-American Multilateral Agreement on Social Security. 


\section{CUESTIONES PRELIMINARES}

A. PERSONAS CON DISCAPACIDAD EN COLOMBIA: ESTUDIOS ESTADÍSTICOS

B. POSICIÓN DE COLOMBIA FRENTE A LOS CONVENIOS INTERNACIONALES SOBRE LAS MATERIAS DE DISCAPACIDAD Y SEGURIDAD SOCIAL

1. LA CONVENCIÓN DE NACIONES UNIDAS SOBRE LOS DERECHOS DE LAS PERSONAS CON DISCAPACIDAD

2. EL CONVENIO MULTILATERAL IBEROAMERICANO DE SEGURIDAD SOCIAL

3. CONVENIOS DE LA ORGANIZACIÓN INTERNACIONAL DEL TRABAJO EN MATERIA DE DISCAPACIDAD.

II. MARCO JURÍDICO: ESPECIAL REFERENCIA AL SISTEMA DE SEGURIDAD SOCIAL COLOMBIANO

A. APROXIMACIÓN AL CONCEPTO DE PERSONA CON DISCAPACIDAD E INVALIDEZ EN COLOMBIA

B. SISTEMA DE SEGURIDAD SOCIAL COLOMBIANO: SINGULARIDADES

C. PROTECCIÓN DE LAS PERSONAS CON DISCAPACIDAD EN EL SISTEMA DE SEGURIDAD SOCIAL COLOMBIANO

III. CONCLUSIONES 


\section{CUESTIONES PRELIMINARES}

El tratamiento de la discapacidad a nivel global, es un tema de especial atención en nuestros días. La Organización Mundial de la Salud (OMS), estima que alrededor del $15 \%$ de la población mundial ${ }^{1}$ son personas con discapacidad y que tal proporción está en aumento. En este mismo sentido, el último Informe Mundial sobre la Discapacidad ${ }^{2}$, nos desvela que: "Más de mil millones de personas viven en todo el mundo con alguna forma de discapacidad; de ellas, casi doscientos millones experimentan dificultades considerables en su funcionamiento. En los años futuros, la discapacidad será un motivo de preocupación aún mayor, pues su prevalencia está aumentando. Ello se debe a que la población está envejeciendo y el riesgo de discapacidad es superior entre los adultos mayores, y también al aumento mundial de enfermedades crónicas tales como la diabetes, las enfermedades cardiovasculares, el cáncer y los trastornos de la salud mental". El citado informe sigue diciendo que: “(...) En todo el mundo, las personas con discapacidad tienen peores resultados académicos, ello es consecuencia de los obstáculos que entorpecen el acceso de las personas con discapacidad a servicios indispensables, en particular la salud, la educación, el empleo, el transporte, o la información". Estos perores resultados académicos, son el reflejo de los impedimentos y barreras que se presentan para este colectivo, y que supone un lastre importante en el proceso de búsqueda de empleo.

Esta situación es preocupante, porque el derecho a un trabajo digno ${ }^{3}$, constituye un hito fundamental histórico para el desarrollo integral de las personas, que en el caso de las personas con discapacidad, este derecho se hace aún más necesario y se materializa en la oportunidad de poder ganarse la vida mediante un trabajo libremente elegido o aceptado en un mercado y un entorno laboral abierto, inclusivo y accesible. Por lo tanto,

\footnotetext{
${ }^{1}$ Ver en el informe: "Discapacidad: Panorama general". [Acceso: 24/04/2017]

http://www.bancomundial.org/es/topic/disability/overview

${ }^{2}$ Este informe de fecha 9 de junio de 2011, emitido conjuntamente por la OMS y el Grupo del Banco Mundial y que lleva por título: "Informe mundial sobre la discapacidad: rompiendo barreras [New World report on disability: Breakind down barriers]", reúne la mejor información disponible sobre la discapacidad con el fin de mejorar la vida de las personas que la padecen. También, ofrece a los gobiernos y a la sociedad civil un análisis exhaustivo de la importancia de la discapacidad y de las respuestas proporcionadas, basado en las mejores pruebas disponibles, y recomendar la adopción de medidas de alcance nacional e internacional. La visión que nos impulsa, es la de un mundo inclusivo en el que todos podamos vivir una vida de salud, comodidad y dignidad.

${ }^{3}$ Lorenzo García, R.; "El futuro de los discapacitados en el mundo: el empleo como factor determinante para la inclusión". Revista del Ministerio e Inmigración $\mathrm{n}^{\mathrm{o}}$ 50/2004, pp. 73-90. El autor de este artículo ha dirigido por mandato del Club de Roma a nivel mundial, el informe titulado: "El futuro de las personas con discapacidad en el mundo. Desarrollo humano y discapacidad", en el que se realiza un profundo análisis del conjunto de problemas que afectan a la discapacidad a nivel mundial, desde la perspectiva de la integración y el reconocimiento pleno de los derechos inherentes a la dignidad de la persona, y desde la óptica del respeto a la diversidad. A través de la experiencia y aportaciones del referido informe, el autor aborda en este trabajo específico para la Revista del Ministerio de Trabajo y Asuntos Sociales la cuestión concreta de la inserción laboral de las personas con discapacidad como factor determinante para una plena integración social. A partir de la constatación de la situación extraordinariamente negativa en materia de empleo, se analizan las diferentes vías o técnicas de intervención conducentes al objetivo común de la integración laboral, Asimismo, se esbozan las líneas generales de una "nueva estrategia para enfrentar viejos problemas", describiendo sus ejes principales; enumerando los principios y criterios de actuación con carácter general; y concretando éstos en una serie de criterios específicos respecto de la inserción laboral de personas con discapacidad. [Acceso: 02/05/2017] http://www.empleo.gob.es/es/publica/pub_electronicas/destacadas/revista/numeros/50/Est04.pdf
}

e-Revista Internacional de la Protección Social, ISNN 2445-3269. 2017, Vol. II, No 2

http://dx.doi.org/10.12795/e-RIPS.2017.i02.07.

Página 72 
el derecho al trabajo de este colectivo, se configura como un derecho dual ${ }^{4}$, porque por un lado, es una libertad -la persona es libre para trabajar- y, por otro, es un derecho social -la persona puede y debe exigir que se establezcan las condiciones reales y efectivas para poder acceder al empleo-, y que además como ha afirmado Lorenzo García: “(...) no vale cualquier empleo; es necesario incorporarse a empleos de mayor calidad" $5 "$

En Colombia ${ }^{6}$, según consta en la última encuesta de población, hay un total de 2.624.898 de personas con discapacidad, con una Tasa de Prevalencia con respecto al total de la población del $6.3 \%$, siendo la distribución por sexo muy igualada: $6,6 \%$ de hombres y $6,1 \%$ de mujeres. En la realidad de los países próximos de América Latina y el Caribe ${ }^{7}$, existen alrededor de ochenta y cinco millones de personas con algún tipo de discapacidad, de los cuales, entre el $80 \%$ y el $90 \%$ están desempleados o no integrados a la fuerza laboral. En esta región, el tema de la discapacidad se cruza con el tema del envejecimiento de la población caracterizado por una alta incidencia de la pobreza y una baja cobertura de los sistemas nacionales de seguridad social.

\section{A. PERSONAS CON DISCAPACIDAD EN COLOMBIA: ESTUDIOS ESTADÍSTICOS $^{8}$}

Para conocer la realidad de la protección social y la problemática actual de las personas con discapacidad en Colombia, es indispensable acceder a los estudios estadísticos de este colectivo. La Administración pública colombiana, dispone de dos Organismos especializados en este tipo de estudios.

Por un lado, el Departamento Administrativo Nacional de Estadística (DANE), que si bien ofrece información muy amplia sobre las condiciones de vida de la población con discapacidad, hoy en día necesitaría realizarse la correspondiente actualización.

Por otro lado, el Registro para la Localización y Caracterización de la Población con Discapacidad (RLCPD), que es una herramienta nacional, dirigida por el Ministerio de Salud y Protección Social colombiano, que permite recoger vía web información sobre dónde están y cómo son las personas con algún tipo de discapacidad residentes en Colombia, $\mathrm{Su}$ objetivo es proveer información estadística sobre las personas en situación de discapacidad en apoyo al desarrollo de la Política Nacional de Atención a

\footnotetext{
${ }^{4}$ García Presas, I.; "El acceso al trabajo de las personas discapacitadas". Anuario da Facultade de Dereito da Universidade da Coruña ${ }^{\circ}$ 17/ 2013, p. 303. [Acceso: 05/05/2017] http://ruc.udc.es/dspace/bitstream/handle/2183/12561/AD_17_2013_art_14.pdf?sequence=1

${ }^{5}$ Lorenzo García, R.; "El futuro de los discapacitados en el mundo: el empleo como factor determinante para la inclusión”. Op. cit., p. 87. [Acceso: 15/05/2017]

http://www.empleo.gob.es/es/publica/pub_electronicas/destacadas/revista/numeros/50/Est04.pdf

${ }^{6}$ Según consta en el último informe del Departamento Administrativo Nacional de Estadística de Colombia (DANE).

${ }^{7}$ Ver en: "Informe Regional sobre la Medición de la Discapacidad. Una mirada a los procedimientos de medición de la discapacidad en América Latina y el Caribe". Grupo de tareas sobre medición de la discapacidad Conferencia Estadística de las Américas (CEA), 2014. [Acceso: 15/05/2017] http://www.cepal.org/deype/noticias/documentosdetrabajo/0/53340/LCL3860e.pdf ${ }^{8}$ Para profundizar sobre este tema, ver en: www.discapacidadcolombia.com [Acceso: 15/05/2017] http://discapacidadcolombia.com/index.php/estadisticas
} 
las Personas con Discapacidad, de los programas y proyectos de prevención, atención, rehabilitación y equiparación de oportunidades.

En la gráfica 1, se refleja la situación comparada de Colombia respecto a la población con discapacidad que alberga en su territorio, frente a la de países de su entorno y España.

Gráfica 1. Distribución porcentual comparativa de Personas con Discapacidad en Colombia, países de su entorno y España

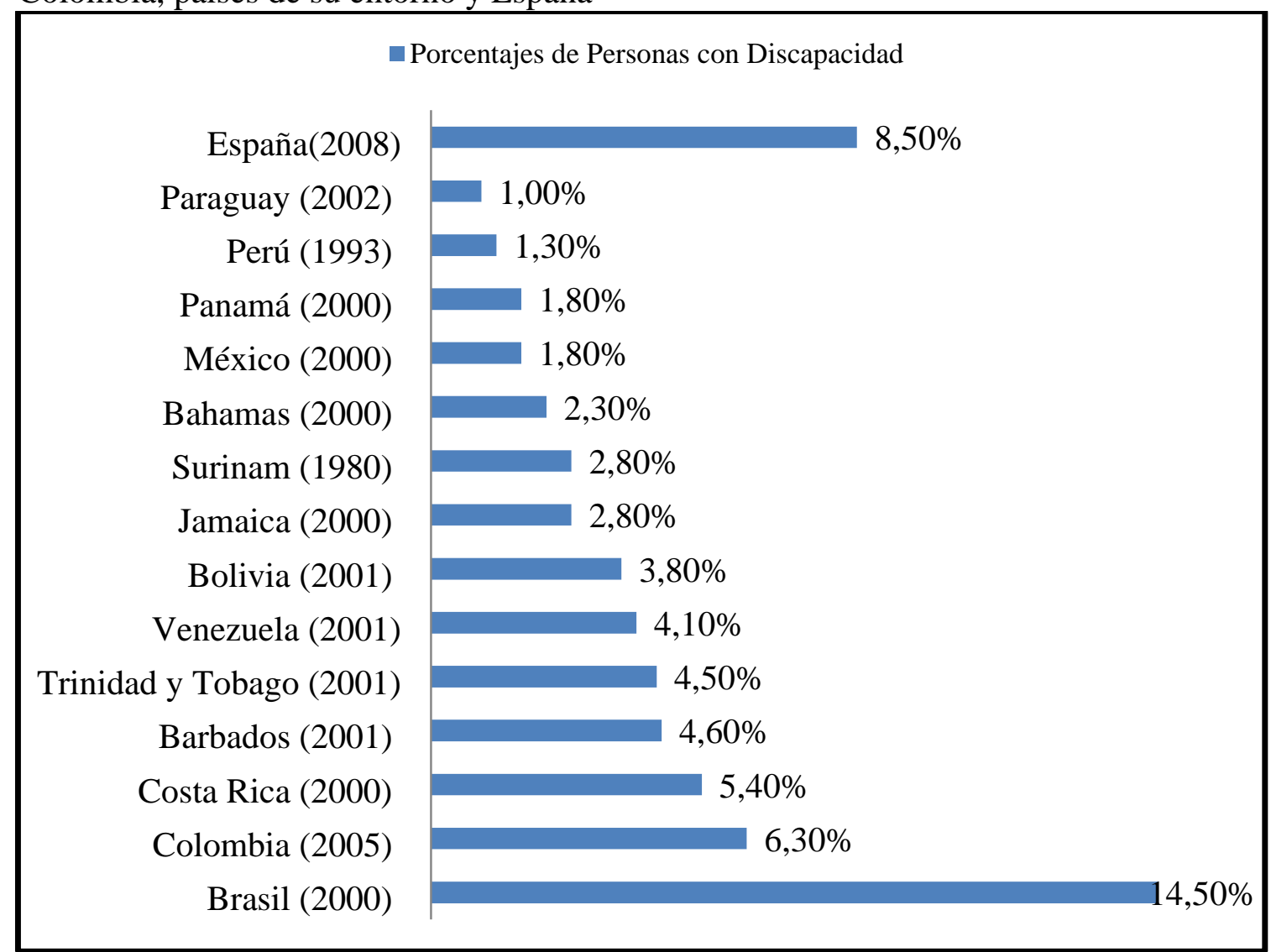

[Fuente: Elaboración propia, a partir de los datos consultados en el Banco Interamericano de desarrollo y Ministerio de Salud y Protección Social de ColombiaSala Situacional de Personas con Discapacidad. Octubre, 2016]

Tabla 1. Distribución por sexo y edad del total de la población, en relación con el colectivo de Personas con Limitaciones Permanentes y Personas con Discapacidad en Colombia

\begin{tabular}{|c|c|c|c|c|c|c|c|}
\hline Personas & $\mathbf{N}^{0}$ & Sexo & $\mathbf{N}^{\mathbf{0}}$ & $\%$ & Edad & $\mathbf{N}^{\mathbf{0}}$ & $\%$ \\
\hline & & $\mathbf{M}$ & 24.078 .673 & 51 & $0-19$ & 17.185 .852 & 35 \\
\hline T: Población & 48.747 .708 & & & & $20-59$ & 26.019 .379 & 53 \\
\hline \multirow[t]{2}{*}{$\%$} & 100 & $\mathbf{H}$ & 24.069 .035 & 49 & $60 \mathrm{y}+$ & 5.542 .477 & 11 \\
\hline & & $\mathbf{M}$ & 1.514 .240 & 49,6 & 0 - 19 & 605.214 & 19,8 \\
\hline Limitaciones & 2.624 .898 & & & & $20-59$ & 1.437 .636 & 47,1 \\
\hline \multirow[t]{2}{*}{$\%$} & 6,3 & $\mathbf{H}$ & 1.536 .977 & 50,4 & $60 y+$ & 1.008 .367 & 33 \\
\hline & & M & 634.236 & 50 & 0 - 19 & 147.178 & 12 \\
\hline Discapacidad & 1.265 .328 & & & & $20-59$ & 542.381 & 43 \\
\hline$\%$ & 2,6 & $\mathbf{H}$ & 629.450 & 50 & $60 y+$ & 575.255 & 45 \\
\hline
\end{tabular}

e-Revista Internacional de la Protección Social, ISNN 2445-3269. 2017, Vol. II, No 2 
[Fuente: Elaboración propia, a partir de los datos consultados en el DANE y en el Ministerio de Salud y Protección Social de Colombia-Sala Situacional de Personas con Discapacidad. Octubre, 2016]

Un estudio del perfil de la población colombiana con Discapacidad desde la perspectiva diferencial, se recoge en tabla 1.

Gráfica 2. Número de Personas con Discapacidad incluidas en el RLCPD por año

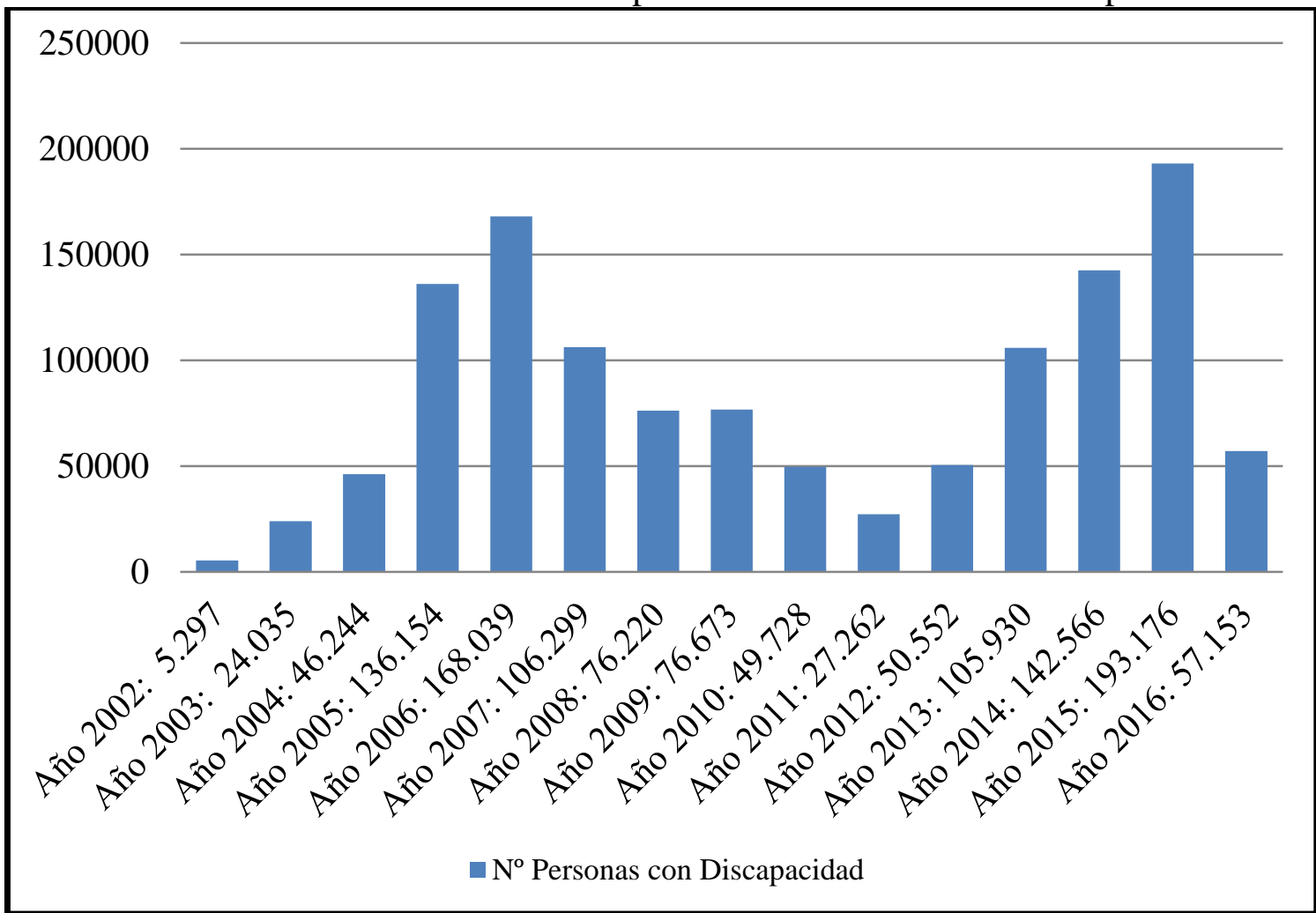

[Fuente: Elaboración propia, a partir de los datos consultados en el DANE y en el

Ministerio de Salud y Protección Social de Colombia-Sala Situacional de Personas con

Discapacidad. Octubre, 2016]

Con la inscripción en el Registro para la Localización y Caracterización de la Población con Discapacidad (RLCPD), se inicia el reconocimiento de los derechos, porque la información del Registro permite:

-Conocer el número de personas con discapacidad y las condiciones en que viven a nivel departamental, distrital y municipal, con el fin de planificar acciones para suplir las necesidades de esta población.

-Disponer de una información veraz sobre las personas con discapacidad, que permita ejecutar adecuadamente programas y proyectos en favor de esta población a nivel municipal, departamental /distrital y nacional.

-Identificar cuáles son las acciones inclusivas que se pueden general a nivel departamental, distrital y municipal con el fin de equiparar las oportunidades para la población con discapacidad. 
Entre los años 2002 y 2010, el Registro fue administrado por el Departamento Administrativo Nacional de Estadística (DANE), quien en el año 2006 tuvo su mayor número de personas registradas y en diciembre del año 2010 fue la entrega de este registro al Ministerio de Salud.

Gráfica 3. Personas con discapacidad en Colombia según el origen de la discapacidad

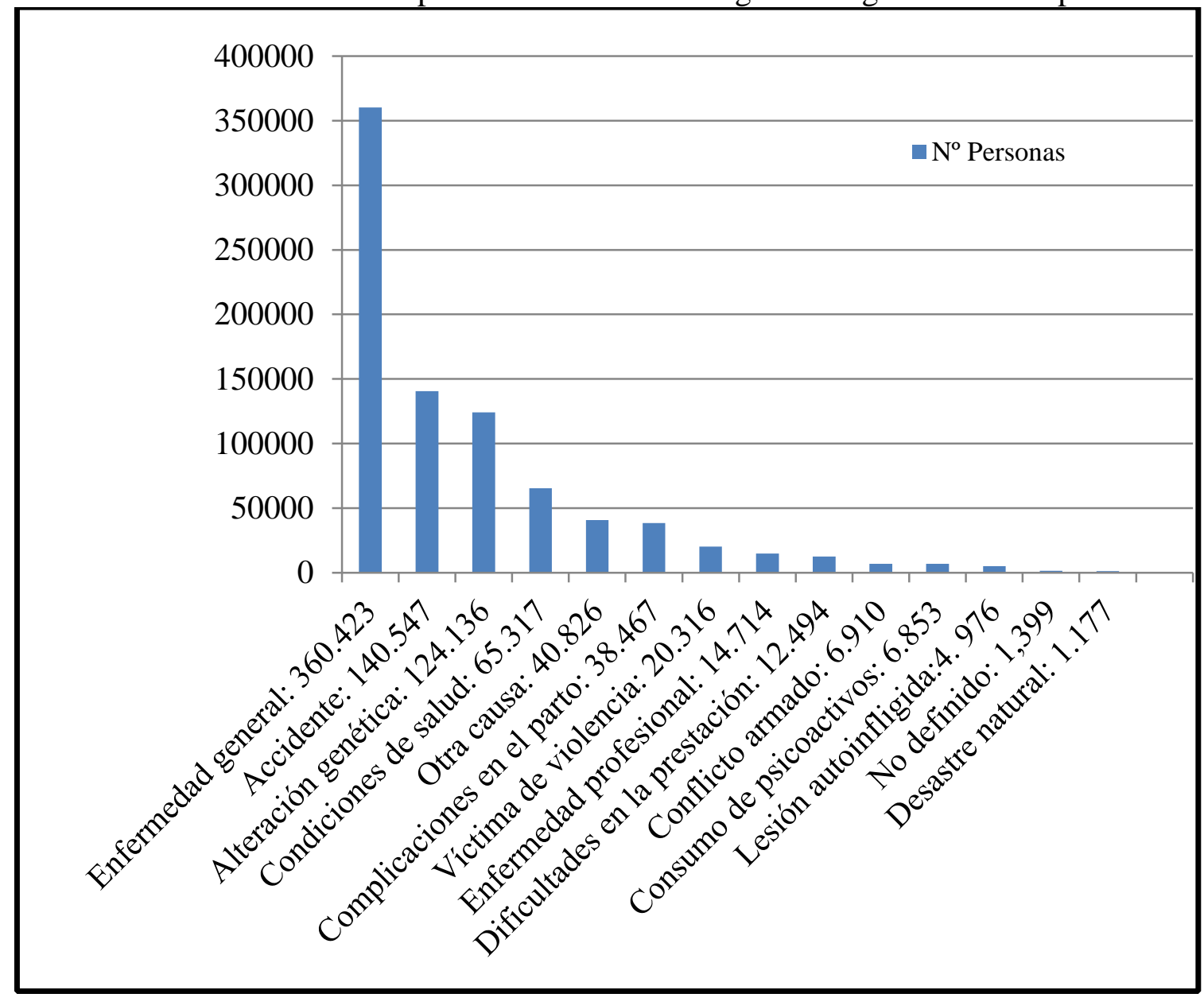

[Fuente: Elaboración propia, a partir de los datos consultados en el DANE y en el Ministerio de Salud y Protección Social de Colombia-Sala Situacional de Personas con Discapacidad. Octubre, 2016]

Tabla 2. Acceso a la Discapacidad por accidente o enfermedad profesional

\begin{tabular}{|c|c|c|c|c|c|c|}
\hline Origen & \multicolumn{6}{|c|}{ PERSONAS CON DISCAPACIDAD POR ACCIDENTE } \\
\hline Causa & $\begin{array}{c}\text { De } \\
\text { tránsito }\end{array}$ & $\begin{array}{l}\text { En el } \\
\text { hogar }\end{array}$ & $\begin{array}{c}\text { De } \\
\text { trabajo }\end{array}$ & $\begin{array}{l}\text { Otro tipo de } \\
\text { accidente }\end{array}$ & Deportivo & $\begin{array}{l}\text { En el centro } \\
\text { educativo }\end{array}$ \\
\hline $\begin{array}{c}\mathrm{N}^{\mathrm{o}} \\
\text { personas }\end{array}$ & 40.123 & 39.301 & 39.079 & 17.655 & 2.673 & 1.521 \\
\hline Origen & \multicolumn{6}{|c|}{$\begin{array}{l}\text { PERSONAS CON DISCAPACIDAD POR ENFERMEDAD } \\
\text { PROFESIONAL }\end{array}$} \\
\hline Causa & $\begin{array}{l}\text { Medio } \\
\text { ambiente } \\
\text { físico del }\end{array}$ & $\begin{array}{l}\text { Carga } \\
\text { de } \\
\text { trabajo }\end{array}$ & $\begin{array}{c}\text { Otra } \\
\text { causa }\end{array}$ & $\begin{array}{c}\text { Condiciones } \\
\text { de } \\
\text { seguridad }\end{array}$ & Contaminant & $\begin{array}{l}\text { Organización } \\
\text { del trabajo }\end{array}$ \\
\hline
\end{tabular}

e-Revista Internacional de la Protección Social, ISNN 2445-3269. 2017, Vol. II, No 2 


\begin{tabular}{ccccccc}
\hline & lugar & física & & & & \\
$\mathrm{N}^{\mathrm{o}}$ & 4.849 & 3.156 & 2.736 & 2.078 & 1.355 & 489 \\
personas & & & & & & \\
\hline
\end{tabular}

[Fuente: Elaboración propia, a partir de los datos consultados en el DANE y en el Ministerio de Salud y Protección Social de Colombia-Sala Situacional de Personas con Discapacidad. Octubre, 2016]

Tabla 3. Personas con Discapacidad en Colombia según variables de actividad y trabajo Personas con Discapacidad según su actividad en los últimos 6 meses antes de la aplicación del registro

\begin{tabular}{|c|c|c|c|c|c|c|}
\hline $\begin{array}{l}\text { Activi- } \\
\text { dad }\end{array}$ & $\begin{array}{l}\text { Trabajar } \\
\text { sin } \\
\text { pensión }\end{array}$ & $\begin{array}{l}\text { Oficios del } \\
\text { hogar }\end{array}$ & $\begin{array}{l}\text { Otra } \\
\text { actividad }\end{array}$ & Trabajando & $\begin{array}{l}\text { Estudian- } \\
\text { do }\end{array}$ & $\begin{array}{l}\text { Buscando } \\
\text { trabajo }\end{array}$ \\
\hline $\begin{array}{l}N^{0} \text { de } \\
\text { PcD }\end{array}$ & 388.427 & 230.818 & 167.550 & 158.559 & 117.436 & 51.890 \\
\hline $\begin{array}{l}\text { Activi- } \\
\text { dad }\end{array}$ & $\begin{array}{l}\text { No } \\
\text { definido }\end{array}$ & $\begin{array}{l}\text { Incapaci- } \\
\text { dad para } \\
\text { trabajar } \\
\text { con } \\
\text { pensión }\end{array}$ & $\begin{array}{l}\text { Autoconsu- } \\
\text { mo }\end{array}$ & $\begin{array}{l}\text { Pensionado } \\
\text {-jubilado }\end{array}$ & No aplica & $\begin{array}{l}\text { Recibien- } \\
\text { do renta }\end{array}$ \\
\hline $\begin{array}{l}N^{0} \text { de } \\
\text { PcD }\end{array}$ & 46.235 & 42.654 & 31.860 & 20.533 & 10.130 & 6.175 \\
\hline \multicolumn{7}{|c|}{ Personas con Discapacidad según la actividad económica en la que trabajan } \\
\hline \multicolumn{2}{|c|}{ Actividad } & Servicios & Otra actividad & Agrícola & \multicolumn{2}{|c|}{ Comercio } \\
\hline \multicolumn{2}{|c|}{$\mathrm{N}^{0}$ de PcD } & 40.659 & 37.112 & 35.776 & \multicolumn{2}{|c|}{29.104} \\
\hline \multicolumn{2}{|c|}{ Actividad } & No definido & \multicolumn{2}{|l|}{ Industria } & \multicolumn{2}{|c|}{ Pecuaria } \\
\hline \multicolumn{2}{|c|}{$\mathrm{N}^{\mathbf{0}}$ de PcD } & 28.717 & \multicolumn{2}{|l|}{9.593} & \multicolumn{2}{|c|}{1.755} \\
\hline \multicolumn{7}{|c|}{ Personas con Discapacidad según como se desempeña en el trabajo } \\
\hline \multicolumn{2}{|c|}{ Actividad } & $\begin{array}{l}\text { Trabajador por } \\
\text { cuenta propia }\end{array}$ & $\begin{array}{l}\text { Obrero/ } \\
\text { empleado } \\
\text { particular }\end{array}$ & No definic & \multicolumn{2}{|c|}{ Jornalero o peón } \\
\hline \multicolumn{2}{|c|}{$\mathbf{N}^{0}$ de PcD } & 62.567 & 34.957 & 28.376 & \multicolumn{2}{|c|}{26.078} \\
\hline \multicolumn{2}{|c|}{ Actividad } & $\begin{array}{l}\text { Empleada/o } \\
\text { doméstico }\end{array}$ & $\begin{array}{l}\text { Obrero/emplea } \\
\text { do del } \\
\text { Gobierno }\end{array}$ & \multicolumn{2}{|c|}{$\begin{array}{l}\text { Trabajador } \\
\text { familiar sin } \\
\text { remuneración }\end{array}$} & $\begin{array}{l}\text { Patrón o } \\
\text { empleador }\end{array}$ \\
\hline \multicolumn{2}{|c|}{$\mathbf{N}^{0}$ de PcD } & 11.462 & 8.549 & 6.384 & \multicolumn{2}{|c|}{4.317} \\
\hline \multicolumn{7}{|c|}{ Personas con Discapacidad según el tipo de contrato que tiene } \\
\hline \multicolumn{2}{|c|}{ Actividad } & contrato & No definido & $\begin{array}{l}\text { A término } \\
\text { indefinido }\end{array}$ & & rmino fijo \\
\hline $\mathbf{N}^{0}$ de $\mathbf{P}$ & & 6.825 & 28.935 & 16.305 & 10 & \\
\hline $\begin{array}{l}\text { Persona } \\
\text { afectad }\end{array}$ & $\begin{array}{l}\text { con Dis } \\
\text { por la mi }\end{array}$ & apacidad se & ún si su capaci & idad para & trabajo & ha visto \\
\hline Afectac & in $\mathrm{S}$ & & NO & NO aplica & $\mathrm{NO}$ & eportado \\
\hline $\mathrm{N}^{0} \mathrm{PcD}$ & & 2.423 & 177.484 & 76.411 & & \\
\hline$\%$ & & & $14 \%$ & $6 \%$ & $2 \%$ & \\
\hline
\end{tabular}

Personas con Discapacidad según si necesita capacitación para...

$\begin{array}{llll}\text { Necesidad } & \begin{array}{l}\text { Si para mejorar su } \\ \text { actividad }\end{array} & \begin{array}{l}\text { Si cambiar de } \\ \text { productiva }\end{array} & \begin{array}{l}\text { actividad } \\ \text { productiva }\end{array} \\ & & \end{array}$

e-Revista Internacional de la Protección Social, ISNN 2445-3269. 2017, Vol. II, N 2 
[Fuente: Elaboración propia, a partir de los datos consultados en el DANE y en el Ministerio de Salud y Protección Social de Colombia-Sala Situacional de Personas con Discapacidad. Octubre, 2016]

Gráfica 4. Afiliación y Régimen respecto al Sistema General de Seguridad Social colombiano de las Personas con Discapacidad frente al conjunto total de la población

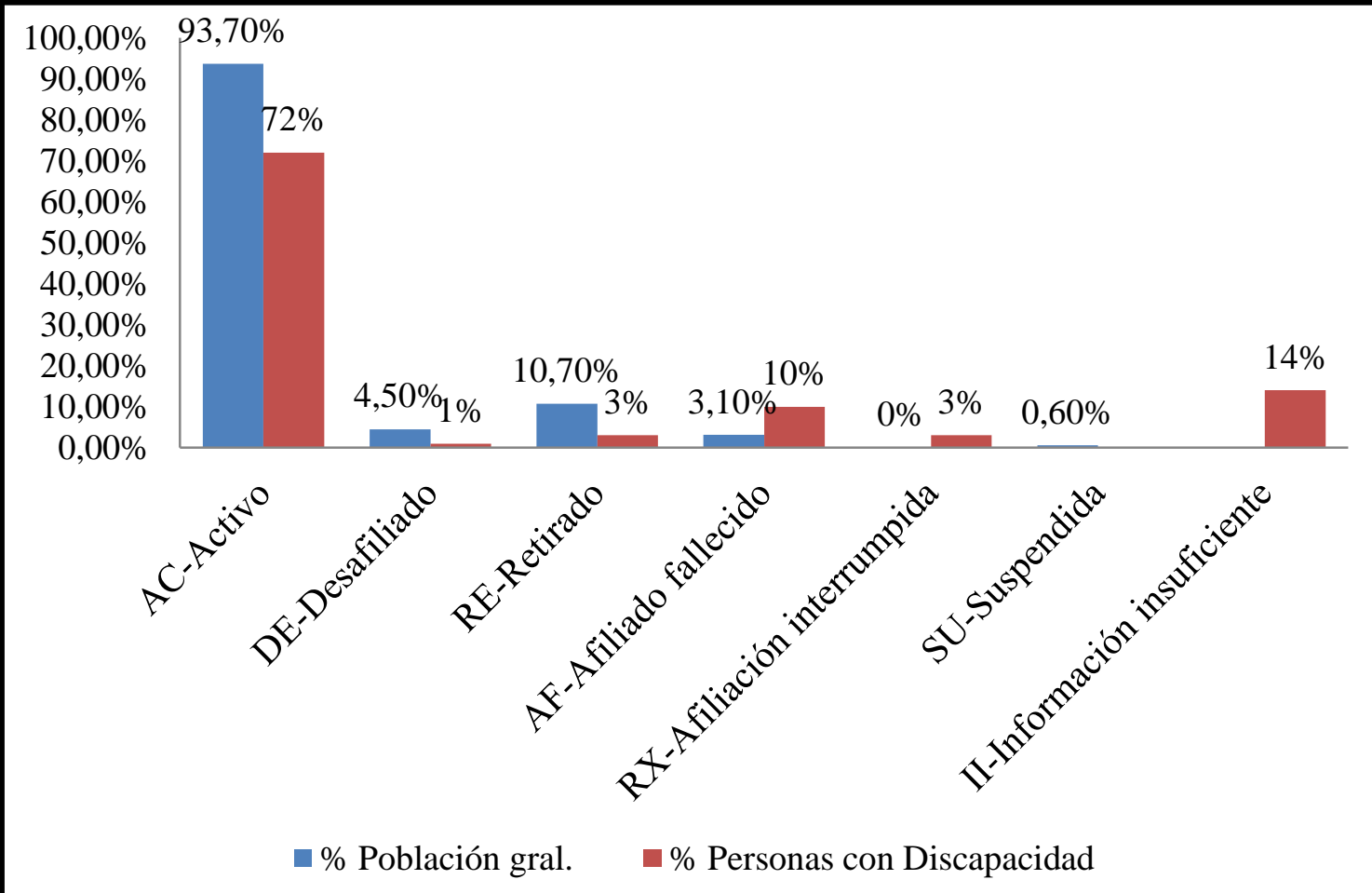




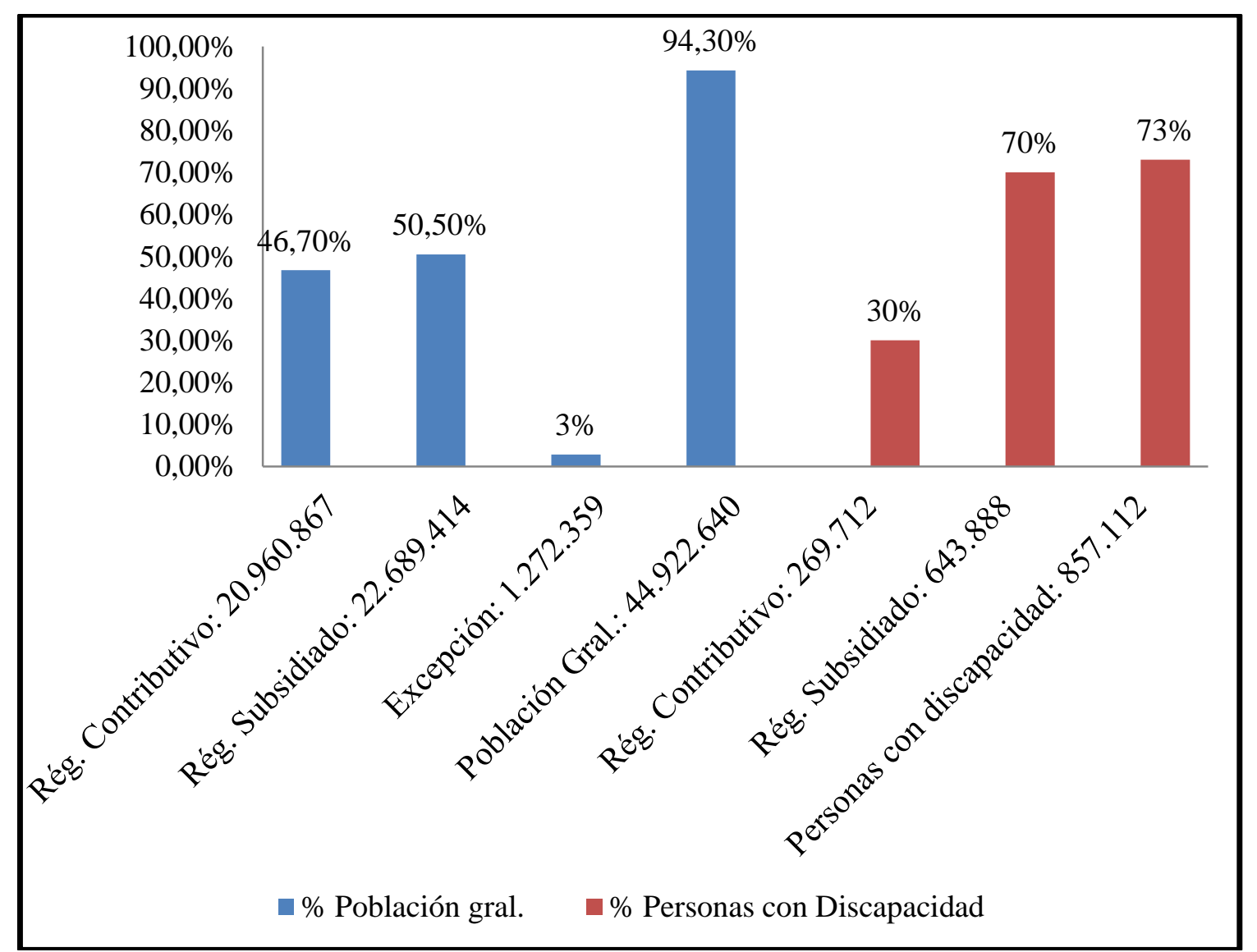

[Fuente: Elaboración propia, a partir de los datos consultados en el DANE y en el Ministerio de Salud y Protección Social de Colombia-Sala Situacional de Personas con Discapacidad. Octubre, 2016]

Gráfica 5. Personas con Discapacidad en Colombia según los ingresos que perciben 


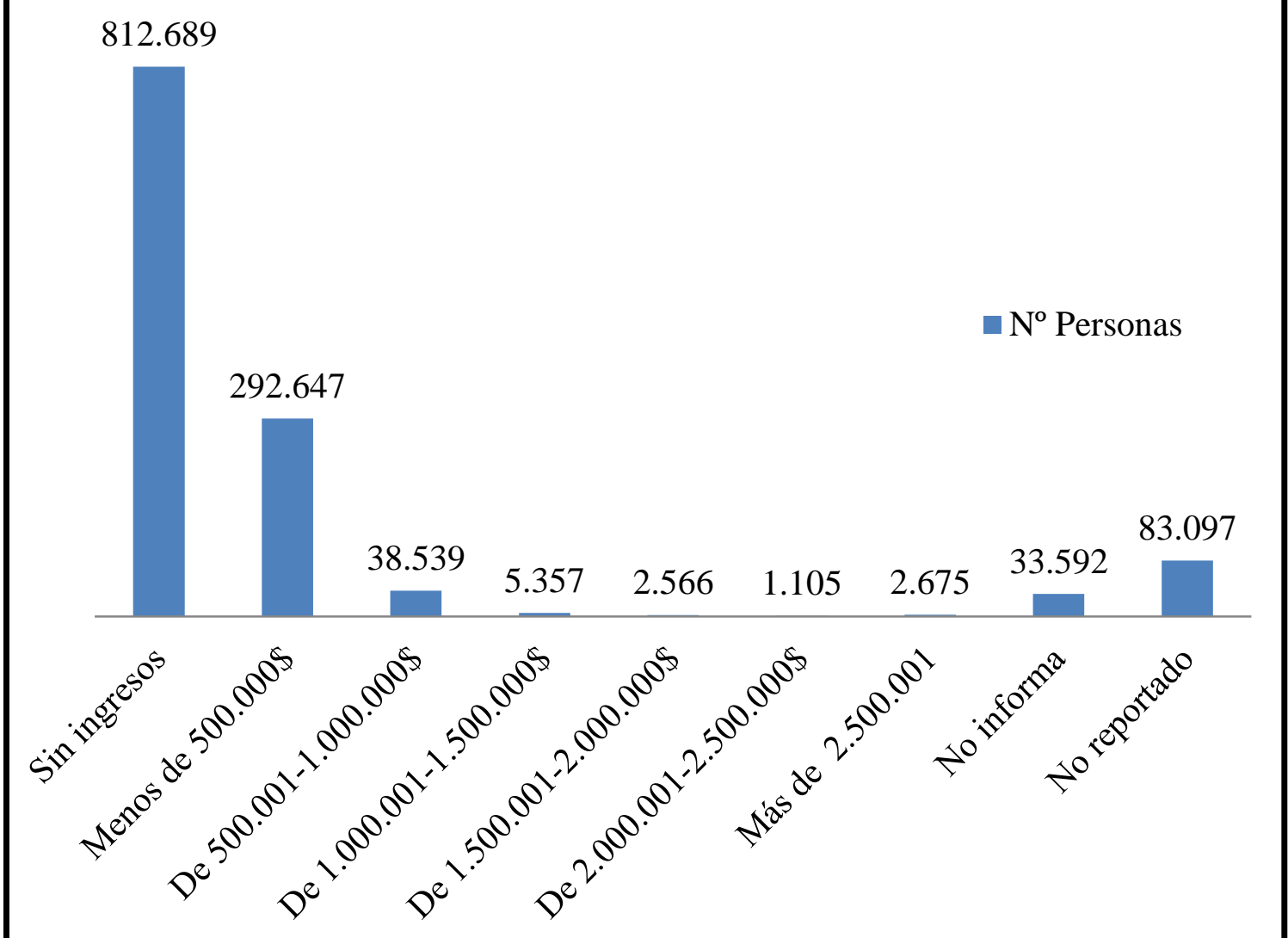

[Fuente: Elaboración propia, a partir de los datos consultados en el DANE y en el Ministerio de Salud y Protección Social de Colombia-Sala Situacional de Personas con Discapacidad. Octubre, 2016]

El 23\% de la población con discapacidad, perciben ingresos inferiores a 500.000 \$, mientras que el $64 \%$ de este colectivo no recibe ningún ingreso.

\section{B. POSICIÓN DE COLOMBIA FRENTE A LOS CONVENIOS INTERNACIONALES SOBRE LAS MATERIAS DE DISCAPACIDAD Y SEGURIDAD SOCIAL}

\section{LA CONVENCIÓN DE NACIONES UNIDAS SOBRE LOS DERECHOS DE LAS PERSONAS CON DISCAPACIDAD}

El gran hito histórico en materia de protección de los Derechos de las Personas con Discapacidad, se va a producir con la aprobación el 13 de diciembre de 2006 en Nueva York, de la Convención de las Naciones Unidas sobre los Derechos de las Personas con Discapacidad (CDPD).

Colombia firmó esta Convención el 30 de marzo de 2007, ratificando la misma el 31 de julio de 2009, mediante la Ley 1346/2009. Posteriormente y cumpliendo con el compromiso adquirido en referencia a la adaptación y armonización de su normativa. También se aprobó y promulgó en su Congreso la Ley 1346/2013 de 27 de febrero, por 
la que se establecen las Disposiciones para Garantizar el Pleno Ejercicio de los Derechos de las Personas con Discapacidad.

Conviene señalar por su singularidad, que esta Convención ha sido calificada como el primer instrumento amplio de Derechos Humanos del siglo XXI, así como el primer tratado internacional de Derechos Humanos que se abre a la firma de organizaciones regionales de integración, como la propia Unión Europea9. Además de recoger los Derechos de las Personas con Discapacidad, también contempla las obligaciones de los Estados de promover, proteger y asegurar tales derechos ${ }^{10}$. Ratificada el 26 de noviembre de 2009 y entrando en vigor en enero de 2011, tanto los Estados miembros como la propia Unión Europea han comenzado a adaptar sus ordenamientos jurídicos a la nueva realidad ${ }^{11}$. Sin embargo, hasta el día de la fecha, no se ha promulgado ninguna directiva, si bien cuenta con la última iniciativa política y legislativa orientada a la lucha contra la discriminación y la igualdad de trato de las personas con discapacidad, que adoptó la Comisión Europea en 2010, es la Estrategia Europea sobre Discapacidad 2010-2020

Al igual que Colombia, España ratificó previamente esta Convención el 3 de diciembre de 2007, entrando en vigor el 3 de mayo de 2008. La adaptación y reforma de la normativa española sobre los Derechos de las Personas con Discapacidad, ha tenido como consecuencia inmediata la elaboración del Real Decreto Legislativo 1/2013, de 29 de noviembre, por el que se aprueba el Texto Refundido de la Ley General de Derechos de las Personas con Discapacidad y de su Inclusión Social ${ }^{13}$. En referencia a la Igualdad

\footnotetext{
${ }^{9}$ Cabra de Luna, M.; "La protección de la discapacidad en el ámbito internacional: la Unión Europea”, en: VV.AA.; Protección social: Seguridad Social y Discapacidad. Estudios en homenaje a Adolfo Jiménez. Cinca. Madrid, 2014, p. 389. También puede consultarse sobre este asunto, en: Cabra de Luna, M.; "El empleo de las personas con discapacidad en el ordenamiento jurídico comunitario y nacional", en: Castillo Díaz, M.; I Congreso Nacional sobre Empleo de las Personas con Discapacidad: Hacia la plena inclusión laboral. UNIA. 2016, p. 9.

${ }^{10}$ Concretamente, la Convención establece como principios generales el respeto de la dignidad inherente a la persona, la autonomía individual, la independencia de cada ser humano, la no discriminación, la participación e inclusión plena y efectivas en la sociedad, la igualdad de oportunidades, el respeto por la diferencia y la aceptación de las personas con discapacidad como manifestación de la diversidad y la condición humana. Cfr.. Cabra de Luna, M.; "La protección de la discapacidad...Op. cit., p. 390.

${ }^{11}$ Sin embargo, al día de hoy queda mucho por hacer, es necesario que la Comisión Europea desarrolle unas directrices que permiten el mainstreaming de la Convención Internacional sobre los Derechos de las Personas con Discapacidad en toda la legislación europea y que revise todo el acervo comunitario actualmente vigente. No le corresponde únicamente a la Unión Europea, realizar su trabajo, también es imprescindible que los Estados miembros realicen sus tareas.

12 Tiene como una de las principales prioridades la incorporación de las personas con discapacidad al mercado laboral. Igualmente se centra en la eliminación de barreras e identifica medidas a escala de la Unión Europea complementarias a las acciones a nivel nacional. También determina los mecanismos necesarios para aplicar la Convención. Asimismo se focaliza en otros aspectos fundamentales para la plena integración y la igualdad de trato de las personas con discapacidad.

Sobre los objetivos, en: VV.AA.; "Des droits pour tous: contribution des organismos de lutte contre les discriminations à l'évaluation de la Stratégie 2010-2020 de L'Union Européenne en faveur des personnes handicapées. Un avis equinet", Bruselas, Equinet European network of equality bodies, diciembre, 2014. También Ballester Pastor, M.; "La lucha contra la discriminación en la Unión Europea". Revista del Ministerio e Inmigración. Derecho social Internacional y Comunitario, no 92/2011, pp. 207-255.

${ }^{13}$ Que deroga expresamente por refundirlas en este texto, la Ley 13/1982 (LISMI), la Ley 51/2003, de 2 de diciembre, de igualdad de oportunidades, no discriminación y accesibilidad universal de las personas con discapacidad (LIONDAU) y Ley 49/2007, de 26 de diciembre, por la que se establece el régimen de infracciones y sanciones en materia de igualdad de oportunidades, no discriminación y accesibilidad universal de las personas con discapacidad.
}

e-Revista Internacional de la Protección Social, ISNN 2445-3269. 2017, Vol. II, No 2

http://dx.doi.org/10.12795/e-RIPS.2017.i02.07.

Página 81 
de oportunidades y no discriminación, se describen las medidas contra la discriminación y las medidas de acción positiva. Se incluye, también por primera vez, las definiciones de todos los tipos de discriminación, directa, indirecta, por asociación y acoso.

\section{EL CONVENIO MULTILATERAL IBEROAMERICANO DE SEGURIDAD SOCIAL}

La situación de Colombia, países de su entorno y España respecto a la firma, ratificación, depósito, acuerdo y aplicación efectiva del Convenio Multilateral Iberoamericano de Seguridad Social, de conformidad a los Artículos 29, 30 y 31.2 CMISS y el 33.3 de AA, es la siguiente:

Tabla 4. Situación de Colombia, países de su entorno y España respecto al CMISS

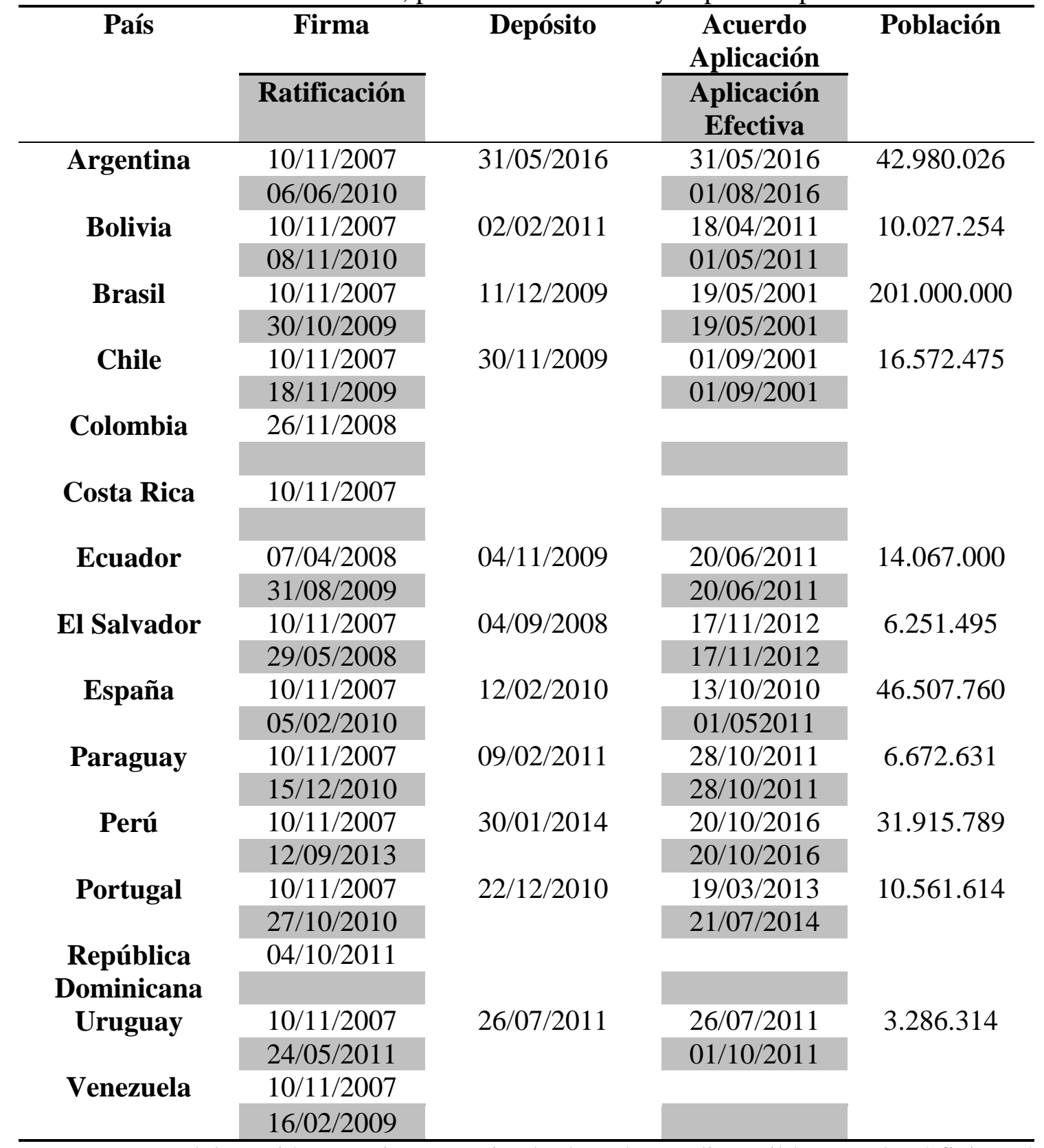

[FUENTE: Elaboración propia a partir de los datos disponibles en la Oficina de Información Diplomática]

e-Revista Internacional de la Protección Social, ISNN 2445-3269. 2017, Vol. II, No 2 
La profesora SÁNCHEZ-RODAS ${ }^{14}$, que ha realizado un profundo estudio sobre el Convenio Multilateral Iberoamericano de Seguridad Social, refiriéndose a la génesis de este Convenio, dice que:"desde sus orígenes, el Convenio Multilateral ha estado íntimamente ligado a la Organización Iberoamericana de Seguridad Social (OISS). Precisamente fue en el congreso que ésta última organizó en el año 2004 donde surgió la idea de su elaboración que comienza a materializarse a partir de 2005 con ocasión de la V Conferencia Iberoamericana de Ministros/Máximos Responsables de Seguridad Social". Esta Conferencia que se celebró en Segovia, tenía como finalidad, "contar con un instrumento único de coordinación de las legislaciones nacionales en materia de pensiones que, con plena seguridad jurídica, garantice los derechos de los trabajadores migrantes y sus familias, protegidos bajo los esquemas de Seguridad Social de los diferentes Estados Iberoamericanos".

Continúa la citada profesora, refiriéndose al Proyecto del Convenio Multilateral, que "se aprobaría dos años más tarde, con motivo de la VI Conferencia Iberoamericana de Ministros y Máximos Responsables de Seguridad Social celebrada en Chile en 2007 siendo aprobado el texto definitivo ese mismo año durante la XVII Cumbre Iberoamericana de Jefes de Estado y de Gobierno celebrada en Santiago de Chile".

GONZÁLEZ ORTEGA ${ }^{15}$, dice que: “(...) de forma sintética, el Convenio Multilateral Iberoamericano de Seguridad Social es una herramienta de coordinación supranacional en materia de protección social que, sin afectar a los respectivos sistemas nacionales, se inscribe en el repertorio de los que, con ámbitos espaciales diferentes, tienen como objetivo proteger los derechos de seguridad social de los trabajadores migrantes y de las personas que dependen de ellos".

Por su parte, JIMÉNEZ FERNÁNDEZ ${ }^{16}$, sostiene que el Convenio Multilateral Iberoamericano, es: "una experiencia pionera porque, plantea lograr un acuerdo en materia de Seguridad Social en un ámbito en el que no existe una previa asociación política que facilite el sustrato jurídico que podría darle apoyo”.

Respecto a la falta de una definición jurídica sobre el término "Coordinación", y ante la necesidad de realizar una aproximación a dicho concepto, SÁNCHEZ-RODAS y otro sector de la Doctrina, afirman que podríamos inferir sus notas características de la

\footnotetext{
${ }^{14}$ Vid. Sánchez-Rodas Navarro, C.; “Aproximación a la coordinación de Regímenes de Seguridad Social en el Reglamento 883/2004 y en el Convenio Multilateral Iberoamericano de Seguridad Social”. ERevista Internacional de la Protección Social no 1 Vol. 1/2016, p 4. [Acceso: 13/02/2017] https://institucional.us.es/revistapsocial/index.php/erips/article/view/2

También sobre este mismo asunto, puede consultarse en: Sánchez-Rodas Navarro, C.; "Sinopsis del Reglamento 883/2004 y del Convenio Multilateral Iberoamericano de Seguridad Social” en: VV.AA.; El Derecho del Trabajo y de la Seguridad Social en la Encrucijada: Retos para la Disciplina Laboral. Laborum. Murcia. 2008; pp. 182-183. [Acceso: 13/02/2017]

https://idus.us.es/xmlui/bitstream/handle/11441/34282/derecho\%20del\%20trabajo.pdf?sequence=1\&isAll owed=y

${ }^{15}$ González Ortega, S.; "El Convenio Multilateral Iberoamericano de Seguridad Social y la cobertura de la Discapacidad”, en: VV.AA.; Protección social: Seguridad Social y Discapacidad. Estudios en homenaje a Adolfo Jiménez. Cinca. Madrid, 2014, pp. 449.

${ }^{16}$ Jiménez Fernández, A.; "Convenio Multilateral Iberoamericano de Seguridad Social” en: VV.AA.; "El Futuro de la Protección Social”. Laborum. Murcia. 2010, p.375.
}

e-Revista Internacional de la Protección Social, ISNN 2445-3269. 2017, Vol. II, N 2 
Jurisprudencia del Tribunal de Justicia de la Unión Europea. Dichas notas, serían las siguientes:

-Coordinación no implica unificación ni armonización de Sistemas de Seguridad Social.

-Tampoco conlleva la derogación, reforma o modificación de los sistemas nacionales de Seguridad Social coordinados que subsisten con todas sus peculiaridades.

-No veda las competencias soberanas de los Estados para legislar en el ámbito de la Seguridad Social.

-La coordinación no es un fin en sí mismo, sino un instrumento para facilitar, en última instancia, la libre circulación de trabajadores en el seno de la Comunidad Iberoamericana (por lo que al Convenio Multilateral se refiere).

-La coordinación permite salvaguardar los derechos adquiridos y en curso de adquisición de los migrantes en el ámbito de la Seguridad social, evitando que los trabajadores migrantes no vean mermados sus derechos y/o expectativas de derecho en materia de Seguridad Social.

-Mediante la técnica de la coordinación el Convenio Multilateral, garantiza a los sujetos incluidos dentro de sus respectivos ámbitos de aplicación un trato igual al dispensado a los trabajadores nacionales ${ }^{17}$.

Otros autores como MIRANDA BOTO ${ }^{18}$, prefieren utilizar "articulación" como término alternativo a coordinación.

Respecto a la posible tutela dispensada a las Personas con Discapacidad por parte del Convenio Multilateral Iberoamericano, coincidimos con González Ortega en afirmar que se trataría de una "tutela indirecta" $"$. Concretándose dicha tutela, de una parte, garantizando las prestaciones económicas o pensiones de invalidez a las que pueden tener derecho trabajadores o profesionales activos que, sea como consecuencia de un accidente de trabajo o de una enfermedad profesional o de un accidente no laboral o de una enfermedad común que pasan a la situación de discapacidad normalmente calificada en las normas de Seguridad Social, y también en el Convenio Multilateral Iberoamericano, como invalidez.

También puede servir para proteger a los discapacitados ${ }^{20}$ a través de prestaciones económicas de orfandad o a favor de familiares, que en muchos ordenamientos, se hacen depender de la condición de persona discapacitada en un alto nivel de los beneficiarios. Siendo particularmente frecuente que esos beneficios económicos causados por el fallecimiento del trabajador activo, se reconozcan a familiares que al

\footnotetext{
${ }^{17}$ Sánchez-Rodas Navarro, C.; "Aproximación a la coordinación de Regímenes de Seguridad Social. Op. cit., pp. 5-6. También en: Sánchez-Rodas Navarro, C.; "Sinopsis del Reglamento 883/2004 y del Convenio Multilateral Iberoamericano de Seguridad Social”. Op. cit., p.184.

18 Miranda Boto, J.; "El Estadio Previo: Algunos Problemas Terminológicos de la Seguridad Social Comunitaria" en VV.AA.; El Reglamento Comunitario. Nuevas Cuestiones. Viejos Problemas. Laborum. Murcia. 2008; pp. 26-28.

${ }^{19}$ González Ortega, S.; "El Convenio Multilateral Iberoamericano de Seguridad Social y la cobertura de la Discapacidad". Op. cit., p. 451.

${ }^{20} \mathrm{Ib} .451-452$
}

e-Revista Internacional de la Protección Social, ISNN 2445-3269. 2017, Vol. II, No 2 
margen de la edad, carezcan de la capacidad personal para el desempeño de un trabajo; o que se atribuyan a los hijos del fallecido (como pensiones de orfandad) si éstos, una vez que han alcanzado la mayoría de edad (hasta este momento normalmente el derecho es incondicionado), pueden ser calificados como personas discapacitadas de un cierto nivel que les impida la obtención de ganancias o recursos como consecuencia del desempeño de un trabajo ${ }^{21}$.

En definitiva, el Convenio Multilateral Iberoamericano, no es un convenio de protección específicamente dirigido a las personas discapacitadas ${ }^{22}$, $\sin _{\text {embargo, como }}$ norma de Seguridad Social, aun cuando no dictada especialmente para la protección de las personas discapacitadas, siempre tiene alguna dimensión tuteladora que repercute mayoritaria o exclusivamente en este tipo de personas ${ }^{23}$.

Como se ha puesto de manifiesto al comenzar este epígrafe, Colombia firmó el Convenio Multilateral Iberoamericano de Seguridad Social, el 26 de noviembre de 2008, sin embargo hasta la fecha no ha ratificado el mismo, por lo que no se podrá hacer efectiva la aplicación del mismo.

Por su parte, España lo ratificó el 12 de febrero de 1010 y se publico junto a su Acuerdo de aplicación el 8 de enero de 2011, entrando en vigor el 1 de mayo de $2011^{24}$.

\section{CONVENIOS DE LA ORGANIZACIÓN INTERNACIONAL DEL TRABAJO EN MATERIA DE DISCAPACIDAD.}

Colombia, ha suscrito y ratificado el convenio número 159 de la Organización Internacional del Trabajo, sobre la readaptación profesional y el empleo; fue ratificado el 7 de diciembre de 1989.

No ha hecho lo mismo con el Convenio 128 sobre la invalidez, vejez y sobrevivientes de 1967. Si este convenio hubiera sido ratificado por Colombia, obligaría al país a extender en gran medida el ámbito de protección en materia de invalidez, el cual con la normatividad vigente está dirigido solo a personas cotizantes al sistema, pues significaría tener que incluir a los aprendices e incluso a personas residentes en el país no vinculadas al Sistema de Seguridad Social en Pensiones ${ }^{25}$.

\footnotetext{
21 Tal como se establece en el art. 2, último párrafo del Convenio Multilateral Iberoamericano de Seguridad Social.

22 Por el contrario, sus "destinatarios naturales son los trabajadores y profesionales activos que se desplazan de un país a otro por motivos de trabajo y, adicionalmente, las personas que dependen de ellos económicamente, esto es, los familiares más directos. Desde este punto de vista, puede decirse que el Convenio Multilateral Iberoamericano de Seguridad Social, es una norma de contenido y de cariz esencialmente profesional". Cif. González Ortega, S.; "El Convenio Multilateral Iberoamericano de Seguridad Social y la cobertura de la Discapacidad”. Op. cit., p. 462.

${ }^{23} \mathrm{Ib} .463$

${ }^{24}$ Ver Tabla 4. También en Sánchez-Rodas Navarro, C.; “Aproximación a la coordinación de Regímenes de Seguridad Social. Op. cit., p. 4. También en: Sánchez-Rodas Navarro, C.; "Sinopsis del Reglamento 883/2004 y del Convenio Multilateral Iberoamericano de Seguridad Social”. Op. cit., p.183.

25 Palacio Velásquez, C.; "Pensiones para las Personas con Discapacidad en el Sistema de Seguridad Social colombiano". Op. cit., p. 78.
}

e-Revista Internacional de la Protección Social, ISNN 2445-3269. 2017, Vol. II, No 2 


\section{MARCO JURÍDICO: ESPECIAL REFERENCIA AL SISTEMA DE SEGURIDAD SOCIAL COLOMBIANO}

\section{A. APROXIMACIÓN AL CONCEPTO DE PERSONA CON DISCAPACIDAD E INVALIDAZ EN COLOMBIA}

Corresponde a los ordenamientos jurídicos de cada país, definir y establecer los presupuestos que se deben contemplar para que una persona sea considerada "persona con discapacidad", o se encuentre en un "estado de invalidez".

Tampoco existe una coincidencia entre los términos de discapacidad e invalidez, por lo que será necesario realizar un detenido estudio para conseguir una aproximación a dichos conceptos.

PALACIO VELÁSQUEZ ${ }^{26}$, apunta que la discapacidad ha sido definida en la Convención Interamericana para la Eliminación de Todas las Formas de Discriminación contra las Personas con Discapacidad, de 7 de julio de 1999, como: "una deficiencia física, mental o sensorial, ya sea de naturaleza permanente o temporal, que limita la capacidad de ejercer una o más actividades esenciales de la vida diaria, que puede ser causada o agravada por el entorno económico y social", especifica esta autora que "sin referirse como se puede evidenciar, a porcentajes de pérdida, sino que simplemente se trata de una situación que limita a la persona en el ejercicio de las actividades cotidianas, de manera que sin importar la gravedad de la deficiencia, el sólo hecho de que una persona no pueda desenvolverse en el medio con el pleno de sus capacidades, la hace beneficiaria de una especial protección por parte del Estado".

Según la legislación española ${ }^{27}$, discapacidad es: "una situación que resulta de la interacción entre las personas con deficiencias previsiblemente permanentes y cualquier tipo de barreras que limiten o impidan su participación plena y efectiva en la sociedad, en igualdad de condiciones con los demás”.

La profesora ALONSO-OLEA GARCÍA, sostiene que persona con discapacidad ${ }^{28}$, es aquella que: "presenta deficiencias físicas, mentales, intelectuales o sensoriales a largo plazo, que al interactuar con diversas barreras puedan impedir su participación plena y efectiva en la sociedad, en igualdad de condiciones con los demás, pero además, debe tener reconocido un grado de discapacidad igual o superior al 33\%".

Por lo tanto, y a la luz de lo expuesto, no basta con que una persona padezca una discapacidad y esta le provoque limitaciones, sino que es necesario que haya un reconocimiento legal de tal condición para poder solicitar ayudas o algún tipo de protección social pública ${ }^{29}$.

\footnotetext{
${ }^{26}$ Palacio Velásquez, C.; "Pensiones para las Personas con Discapacidad en el Sistema de Seguridad Social colombiano". Diálogos de Derecho y Política no 14/2014; p. 79. [Acceso: 25/11/2016] https://discapacidadcolombia.com/phocadownloadpap/PUBLICACIONES_ARTICULOS/Pensiones_disc apacidad.pdf

27 Véase el artículo 2.a) del Real Decreto Legislativo 1/2013, de 29 de noviembre, por el que se aprueba el Texto Refundido de la Ley General de derechos de las personas con discapacidad.

${ }^{28}$ Alonso-Olea García, B.; El régimen jurídico de la protección social del minusválido. Cívitas. Madrid. 1997. Adviértase que el término "minusválido" ha evolucionado y se ha transformado por el actual "discapacitado".

${ }^{29}$ Alonso-Olea García, B.; "La protección social de las personas con discapacidad”. Temas para el debate. $\mathrm{n}^{\mathrm{o}} 248 / 2015, \mathrm{p} 26$.
}

e-Revista Internacional de la Protección Social, ISNN 2445-3269. 2017, Vol. II, No 2 
La Sentencia de la Corte Constitucional de Colombia T-122/10 de 18 de febrero de 2010, define y diferencia los conceptos de "discapacidad" e "invalidez", remitiéndose a su vez a la sentencia T-198 de 2006, en la que se especificó que: "los conceptos de discapacidad e invalidez son disímiles, siendo el último una especie dentro del género de las discapacidades". Puntualmente se dijo: "se encuentra establecido que se presenta una clara diferencia entre los conceptos de discapacidad e invalidez. En efecto, podría afirmarse que la discapacidad es el género, mientras que la invalidez es la especie, y en consecuencia no siempre que existe discapacidad necesariamente nos encontramos frente a una persona invalida. La invalidez sería el producto de una discapacidad severa." La discapacidad, implica el padecimiento de una deficiencia física o mental que limite las normales facultades de un individuo, lo cual armoniza con las definiciones propuestas en la Convención Interamericana para la eliminación de todas las formas de discriminación contra las personas con discapacidad. En éstas se habla, de manera idéntica, de 'persona impedida' y 'persona con discapacidad', respectivamente. La invalidez ha sido asumida en el contexto internacional como la reducción de la capacidad para el trabajo a consecuencia de limitaciones físicas o mentales debidamente probadas. Esta idea ha sido adoptada en el contexto jurídico nacional, que define a la invalidez como una pérdida que excede el $50 \%$ de la facultad para laboral, lo que presupone la valoración de la merma.

Sin embargo, como se ha puesto de manifiesto en el apartado primero del primer epígrafe, dedicado a la Convención Internacional sobre los Derechos de las Personas con Discapacidad, tanto España como Colombia firmaron y ratificaron dicho Convenio, cuyo Considerando e) reconoce que "la discapacidad es un concepto que evoluciona y que resulta de la interacción entre las personas con deficiencias y las barreras debidas a la actitud y al entorno que evitan su participación plena y efectiva en la sociedad, en igualdad de condiciones con los demás".

Por su parte, el Artículo 1, define la discapacidad: "Las personas con discapacidad incluyen a aquellas que tengan deficiencias físicas, mentales, intelectuales o sensoriales a largo plazo que, al interactuar con diversas barreras, puedan impedir su participación plena y efectiva en la sociedad, en igualdad de condiciones con los demás".

En definitiva, podemos afirmar que en los últimos tiempos, la protección de las personas con discapacidad en Colombia y España, ha experimentado un notable progreso, pasando del "modelo médico rehabilitador" al "modelo social" que pone el énfasis en la rehabilitación de una sociedad, que ha de ser concebida y diseñada para hacer frente a las necesidades de todas las personas, gestionando las diferencias e integrando la diversidad.

\section{B. SISTEMA DE SEGURIDAD SOCIAL COLOMBIANO: SINGULARIDADES}

El Sistema de Seguridad Social Colombiano, está dirigido por el Ministerio de Salud y protección Social y el Ministerio de Trabajo y reglamentado primordialmente por la Ley de Seguridad Social Colombiana: la Ley 100/1993 de 23 de diciembre.

e-Revista Internacional de la Protección Social, ISNN 2445-3269. 2017, Vol. II, No 2 
Expedida por el Congreso de Colombia ${ }^{30}$, se divide en cuatro secciones que se refieren a los componentes principales del Sistema:

-El primer libro: trata sobre el Sistema general de Pensiones.

-El segundo libro: trata el Sistema General de Seguridad Social en Salud.

-El tercer libro: trata el Sistema General de Riesgos Laborales. Denominación modificada por la Ley 1562 de 2012 a "Sistema General de Riesgos Laborales".

-El cuarto libro: trata de los servicios sociales complementarios.

Como singularidad del sistema, y su diferencia con el ordenamiento jurídico español, hay que señalar que la propia Ley 100/1993 que regula el Sistema General de Seguridad Social, incluye también en la misma norma el "Sistema General de Riesgos Laborales"31, concentrando en un mismo texto legislativo la protección y la prevención.

\section{PROTECCIÓN DE LAS PERSONAS CON DISCAPACIDAD EN EL SISTEMA DE SEGURIDAD SOCIAL COLOMBIANO}

En los últimos años, ha aumentado en Colombia el interés incluso por incluir el estudio de la discapacidad en la enseñanza de la Seguridad Social ${ }^{32}$.

El alcance y contenido del derecho a la seguridad social, se configura como la protección a las personas que están en imposibilidad física o mental para obtener los medios de subsistencia que le permitan llevar una vida digna a causa de la vejez, del desempleo o de una enfermedad o incapacidad laboral.

El derecho a la pensión de invalidez es uno de los mecanismos que, en virtud del derecho a la seguridad social, protege a las personas cuando padecen de una discapacidad que disminuye o anula su capacidad laboral lo que les dificulta o impide obtener los recursos para disfrutar de una vida digna.

Es importante hacer un estudio normativo, con el fin de identificar el desarrollo que existe en Colombia en materia de protección a las personas con discapacidad, específicamente en materia de pensiones, pues si bien en un principio solo existía en el ordenamiento jurídico colombiano una pensión que protegiera a las personas frente a la invalidez, en la actualidad se ha pasado a una visión más proteccionista, en la que no solo la ley prevé figuras que buscan garantizar los derecho de las personas con discapacidad y su especial protección en el ordenamiento jurídico, sino que también existe un amplio desarrollo por parte de la Corte Constitucional, por medio del cual se

\footnotetext{
${ }^{30}$ Las leyes en Colombia proceden del Congreso, Consejo Nacional Electoral y la Presidencia de la República.

${ }^{31}$ En España, la regulación de la Prevención de Riesgos Laborales, se realiza mediante la Ley 31/1995 de 8 de noviembre de Prevención de Riesgos Laborales y otras normas concordantes, pero en instrumentos jurídicos externos a la regulación del Régimen de Seguridad Social.

${ }^{32}$ Gómea Rúa, N., Duque Quintero, S. y Quintero Quintero, M.; "El estudio de la discapacidad como una tendencia actual en la enseñanza del derecho de la seguridad social", Justicia Juris, na 2 Vol. 10/2014, pp 71-82. [Acceso: 13/02/2017] http://www.scielo.org.co/pdf/jusju/v10n2/v10n2a08.pdf
}

e-Revista Internacional de la Protección Social, ISNN 2445-3269. 2017, Vol. II, No 2 
han ampliado las disposiciones existentes en las normas, para hacer extensiva la protección a las personas calificadas con una pérdida de capacidad laboral inferior al $50 \%{ }^{33}$.

Una relación no exhaustiva de las diferentes pensiones que se han ido forjando mediante el desarrollo normativo y jurisprudencial en Colombia es la siguiente:

-Pensión de invalidez para personas con discapacidad.

Aparece por la Sentencia T-483 de 2014, que señala que "una persona que haya nacido con discapacidad y haya laborado y cotizado al sistema por varios años, no puede ser considerada inválida desde su nacimiento".

-Pensión para jóvenes con invalidez.

La Corte Constitucional en la Sentencia T-777 de 2009, indicó que el parágrafo $1^{\circ}$ del artículo $1^{\circ}$ de la Ley 860 de 2003, debe ser aplicado no solo a menores de 20 años sino en general a toda la población joven entre los 14 y 26 años de edad, postura que ha sido reiterada en otros fallos como la Sentencia T-839 de 2010, T-506 de 2012, T-819 de 2013, T-443 de 2014 y T-580 de 2014 entre otras.

-Pensión sustitutiva para los hijos inválidos.

El artículo 13, apartado c) de la Ley 797 de 2003, prevé que deberán acreditar el parentesco con el causante, la dependencia económica sobre el padre pensionado al momento de su muerte y su condición de invalidez, sentencia T- 692 de 2006.

-Pensión para padres con hijos con discapacidad.

Nace con la Ley 797 de 2003, al señalar que cuando alguno de los padres trabajadores cuyo hijo tenga invalidez debidamente calificada y hasta tanto permanezca en este estado y continúe como dependiente de alguno de los padres, tendrá derecho a recibir la pensión especial de vejez a cualquier edad, siempre que haya cotizado al Sistema General de Pensiones cuanto menos el mínimo de semanas exigido en el régimen de prima media para acceder a la pensión de vejez. En definitiva, los padres con hijos con discapacidad, podrán pensionarse una vez cumplan las semanas de cotización que exige la ley sin importar la edad, según la Sentencia C-758 de 2014 de la Corte Constitucional.

-Pensión de vejez a los 55 años por discapacidad.

Se regula en el artículo $9^{\circ}$ de la Ley 797 de 2003, que pese a establecer que para tener el derecho a la pensión de vejez, el afiliado debe haber cumplido 57 años de edad si es mujer y 62 si es hombre, así como haber cotizado un mínimo de mil semanas en cualquier tiempo.

33 Palacio Velásquez, C.; "Pensiones para las Personas con Discapacidad en el Sistema de Seguridad Social colombiano". Op. cit.; p. 77-79. 
El apartado $4^{\circ}$, señala que se exceptúan de estos requisitos las personas con una invalidez del $50 \%$ o más, que cumplan 55 años de edad y que hayan cotizado en forma continua o discontinua 1000 o más semanas al régimen de seguridad social establecido en la Ley 100 de 1993.

-Pensión para las víctimas con discapacidad.

Nace a raíz de la Sentencia C-767 de 2014 de la Corte Constitucional, consistente en un salario mínimo para las víctimas del conflicto armado, que perdieron su capacidad laboral y no tienen otra alternativa pensional.

-Pensión subsidiada.

Consiste en una ampliación de la cobertura mediante un subsidio a las cotizaciones para pensiones de la población que por su condición socioeconómica no tienen acceso a los sistemas de seguridad social, que surgió como un programa del Consorcio Prosperar ${ }^{34}$, que nació con la Ley 100 de 1993 con la creación del Fondo de Solidaridad Pensional como una cuenta especial de la Nación, desarrollada por las Leyes 1151 de 2007 y 1187 de 2008, reglamentada con el Decreto 4944 de 2009.

-Pensión familiar.

Creada por la Ley 1580 de 2012 y por la Sentencia C-613 de 2013, reglamentada por el Decreto 288 de 2014, que permite sumar los aportes a pensión con su cónyuge o compañero permanente, para tener acceso a una pensión que les permita llevar una vida digna.

-Pensión de invalidez.

Es para la persona que sea declarada inválida por enfermedad o por accidente, que haya cotizado cincuenta semanas dentro de los últimos tres años inmediatamente anteriores a la fecha de estructuración, esto según el artículo $1^{\circ}$ de la Ley 860 de 2003, que modificó el artículo 39 de la Ley 100 de 1993.

\section{CONCLUSIONES}

En los últimos tiempos, la protección de las personas con discapacidad en Colombia ha experimentado un notable progreso, pasando del "modelo médico rehabilitador" al "modelo social" que pone el énfasis en la rehabilitación de una sociedad, que ha de ser concebida y diseñada para hacer frente a las necesidades de todas las personas, gestionando las diferencias e integrando la diversidad.

Los estudios estadísticos sobre la situación de las personas con discapacidad en Colombia, desvelan una situación preocupante, 2.624 .898 poseen algún tipo de discapacidad, lo que representan un $6,3 \%$ sobre el total de la población. También se detectan para este colectivo las peores condiciones laborales y los niveles más bajos de retribuciones.

\footnotetext{
${ }^{34}$ Sustituido hoy por el consorcio "Colombia Mayor".

e-Revista Internacional de la Protección Social, ISNN 2445-3269. 2017, Vol. II, No 2 
La posición de Colombia frente a los Convenios Internacionales sobre las materias de Discapacidad y Seguridad Social, es diversa. Respecto a la Discapacidad, ha firmado, ratificado y adaptado su normativa a la Convención Internacional sobre los Derechos de las Personas con Discapacidad. Sin embargo, en materia de coordinación de la Seguridad Social, aunque ha firmado el Convenio Multilateral Iberoamericano de Seguridad Social, en la actualidad no lo ha ratificado.

Los conceptos de discapacidad e invalidez son disímiles en Colombia, siendo el último una especie dentro del género de las discapacidades. En efecto, podría afirmarse que la discapacidad es el género, mientras que la invalidez es la especie, y en consecuencia no siempre que existe discapacidad necesariamente nos encontramos frente a una persona invalida. La invalidez sería el producto de una discapacidad severa.

Como singularidad del sistema de Seguridad Social colombiano, y su diferencia con el ordenamiento jurídico español, hay que señalar que la propia Ley 100/1993 que regula el Sistema General de Seguridad Social, incluye también en la misma norma el "Sistema General de Riesgos Laborales"35, concentrando en un mismo texto legislativo la protección y la prevención.

Se evidencia un amplio desarrollo en la materia de pensiones o prestaciones económicas de las personas con discapacidad. En un principio, su sistema de Seguridad Social Integral, reglamentado primordialmente por la Ley 100 de 1993, contenía una única pensión frente a la invalidez; sin embargo, en años posteriores se ha producido un amplio desarrollo jurisprudencial y normativo que ha contribuido a extender esta protección a un mayor número de personas.

Las prestaciones de Colombia tienen una cobertura más amplia y que sus requisitos hacen que las prestaciones existentes, realmente sean accesibles por los destinatarios de esa protección especial, lo cual no se evidencia en otros países, donde los requisitos son tan exigentes, que difícilmente las personas pueden acceder a las pensiones allí consagradas, así que por esta parte puede decirse que Colombia tiene esta ventaja. Sin embargo, el legislador se ha quedado corto con las diferencias en cuanto a requisitos que estipula entre estas pensiones especiales y las pensiones ordinarias, obviándose así la gran dificultad que tienen estas personas para acceder a un empleo y por consiguiente para cotizar al sistema, ya que en casi todos los casos, las semanas que se exigen no son muy diferentes a las que se les exigen a los demás, como es el caso de la pensión anticipada de vejez para padre o madre cabeza de familia con un hijo con discapacidad, caso en el cual se exigen las mismas semanas que en la pensión ordinaria y la única diferencia es que no se exige una edad mínima.

\footnotetext{
${ }^{35}$ En España, la regulación de la Prevención de Riesgos Laborales, se realiza mediante la Ley 31/1995 de 8 de noviembre de Prevención de Riesgos Laborales y otras normas concordantes, pero en instrumentos jurídicos externos a la regulación del Régimen de Seguridad Social.
} 